\title{
ANALISA MENGGUNAKAN METODE ANALITYCAL HIERARCHY PROCESS (AHP) UNTUK MENENTUKAN KUALITAS PELAYANAN PADA NASABAH BANK
}

\author{
Yulvia Nora Marlim ${ }^{1}$ \\ ${ }^{1}$ Sekolah Tinggi Ilmu Komputer Pelita Indonesia, Jln Ahmad Yani 78-88 Pekanbaru \\ email: yulvia.nora@lecturer.pelitaindonesia.ac.id
}

\begin{abstract}
Abstract kepuasan tidak semata-mata didapat dari kualitas jasa tetapi juga melalui kualitas pelayanan yang diberikan dengan memperhatikan keinginan dan kebutuhan dari nasabah. Penelitian ini bertujuan untuk menganalisa dan merancang software penentu kepuasan nasabah terhadap kualitas pelayanan yang diberikan Bank. Tata penilaian tersebut meliputi focus (focus) pada nasabah, sulusi (solution) yang diberikan kepada nasabah, ketepatan (accuracy) dalam menyampaikan informasi, waktu (time) pelayanan yang cepat dan menyapaikan berbagi produk pada bank dengan jelas (explanation). Untuk mendapatkan hasil surey yang cepat, tepat dan akurat yang diberikan nasabah maka analisan dan perancangan software menggunakan metode Analitycal Hierarchy Process (AHP). Metode Analitycal Hierarchy Process (AHP) untuk mengetahui ketepatan nilai yang diiberikan oleh nasabah dengan cara pengisian angket secara komputerisasi oleh nasabah.hasil dari penilitian ini adalah diperolehnya informasi dengan cepat, tepat dan akurat dengan pengisian angket secara terkomputerisasi dengan menggunakan metode Analitycal Hierarchy Process (AHP) serta informasi mengenai kualitas pelayanan pada bank.
\end{abstract}

Keywords: Analitycal Hierarchy Process, Angket, Kualitas pelayanan, Software

\section{PENDAHULUAN}

Kualitas pelayanan erat kaitannya dengan kepuasan nasabah. Apabila nasabah puas dengan kualitas pelayanan yang diberikan oleh karyawan maka nasabah akan merasa nyaman dan aman dalam melakukan berbagai macam transaksi pada bank. Bank merupakan salah satu instansi atau perusahaan yang mengutamakan pelayanan. Jika ingin mendapatkan nasabah yang banyak, maka pihak bank harus memberikan pelayanan yang prima kepada nasabahnya guna membentuk citra yang baik. Apabila kualitas pelayanan tidak dijaga dan ditingkatkan dengan baik maka nantinya akan kalah bersaing dengan bank lain dan akhirnya kepuasan nasabah terhadap bank tersebut menjadi kurang dan nasabah dapat berpindah ke bank lain.

BCA setiap enam bulan sekali biasanya akan melakukan survey kepuasan nasabah terhadap pelayanan yang diberikan. Survey ini dilakukan pada 3 bank BCA yang berada di Pekanbaru, yaitu Cabang RBC, Cabang Juanda dan Cabang A.
Yani. Survey ini bertujuan untuk mementukan BSQ (Branch Service Quality) yaitu untuk menentukan kualitas pelayanan pada ketiga cabang tersebut. Suvey yang dilakukan oleh bank dengan cara membayar perusahaan survey tersebut untuk melakukan survey dengan cara menelfon nasabah satu persatu dengan cara pemilihan nasabahnya secara acak, sehingga membutuhkan biaya yang besar. Survey ini memiliki bobot 1 sampi 5, dimana 1 (satu) untuk kategori sangat kurang, 2 (dua) untuk kurang, 3 (tiga) untuk cukup, 4 (empat) untu baik, dan 5 (lima) untuk sangat baik.

Dalam penelitian ini, peneliti ingin membuat sebuah aplikasi untuk menentukan kepuasan nasabah terhadap kualitas pelayanan dari ketiga cabang tersebut dengan cara pengisian angket secara komputerisasi yang perhitungannnya menggunakan metode Analiticaly Hierarchy Process (AHP). Sehingga hasil yang diinginkan lebih 
cepat dan akurat serta untuk menghemat biaya dan waktu perusahaan.

\section{METODE PENELITIAN}

\subsection{Sistem Penunjang Keputusan}

Sistem penunjang keputusan adalah sekumpulan elemen yang saling berhubungan untuk membentuk suatu kesatuan dalam proses pemilihan berbagai alternative tindakan guna menyelesaikan suatu masalah, sehingga masalah tersebut dapat diselesaikan secara efektif dan efisien ( Singkil, 2015)

Sistem pendukung keputusan merupakan system informasi interaktif yang menyediakan informasi, pemodelan, dan manipulasi data. System digunakan untuk pengambilan keputusan dalm situasi yang semi terstruktur dan situasi yang tidak terstruktur (kusrini, 2007).

Tujuan dari system pendukung keputusan adalah (kusrini, 2007) :

1. Membantu manajer dalam pengambilan keputusan atas masalah semi terstruktur

2. Mendukung pertimbangan manajer bukan dimaksudkan untuk menggantikan fungsi manajer.

3. Meningkatkan efektifitas yang diambil oeh manajer dari pada perbaikan efesiensi.

4. Memungkinkan pengambilan keputusan secara cepat dengan biaya yang rendah.

5. Peningkatan produktifitas.

6. Meningkatkan kualitas keputusan yang dibuat.

7. Berdaya saing.

8. Mengatasi keterbatasan kognitif dalam pemrosesan dan penyimpanan.

\subsection{Analiticaly Hierarchy Process (AHP)}

Menurut (firdaus et al., 2016) Analiytical

Hierarchy Process (AHP) dapat menyelesaikan masalah multikriteria yang kompleks menjadi satu hirarki. Peralatan utama AHP adalah sebuah hierarki fungsional dengan input utama persepsi manusia.

Cara kerja AHP adalah dengan menyederhanakan suatu permasalahan kompleks yang tidak terstruktur, strategic dan dinamik menjadi bagian-bagian. Prinsip kerja AHP adalah sebagai berikut :

1. Menentukan tujuan/sasaran, kriteria dan alternative

2. Menyusun hirarki dari kriteria dan alternative

3. Member nilai alternative dan kriteria
4. Memeriksa konsistensi penilaian alternative dan kriteria

5. Menentukan prioritas kriteria dan alternative.

Untuk menentukan prioritas dari beberapa criteria dengan melakukan analisa perbandingan berpasangan (pairwise comparision) dari masing-masing criteria untuk menghasilkan bobot relative antar criteria maupun alternative. Suatu criteria akan dibandingkan dengan criteria lainnya dalam hal seberapa penting terhadap pencapaian tujuan diatasnya (saaty, 2986).

Tabel 1. Penilaian Perbandingan Berpasangan

\begin{tabular}{|c|c|c|}
\hline $\begin{array}{c}\text { Tingkat } \\
\text { Kepenti } \\
\text { ngan }\end{array}$ & Defenisi & Keterangan \\
\hline 1 & $\begin{array}{l}\text { Sama } \\
\text { Pentingnya }\end{array}$ & $\begin{array}{l}\text { Kedua elemen } \\
\text { mempunyai } \\
\text { pengaruh yang } \\
\text { sama }\end{array}$ \\
\hline 3 & $\begin{array}{ll}\text { Sedikit } & \text { lebih } \\
\text { penting } & \end{array}$ & $\begin{array}{l}\text { Pengalaman } \\
\text { dan penilian } \\
\text { sangat } \\
\text { memihak satu } \\
\text { elemen } \\
\text { dibandingkan } \\
\text { dengan } \\
\text { pasangannya }\end{array}$ \\
\hline 5 & Lebih penting & $\begin{array}{l}\text { Satu elemen } \\
\text { sangat disukai } \\
\text { dan secara } \\
\text { praktis } \\
\text { domonasinya } \\
\text { sangat nyata, } \\
\text { dibandingkan } \\
\text { dengan elemen } \\
\text { pasangannya }\end{array}$ \\
\hline 7 & Sangat penting & $\begin{array}{l}\text { Suatu elemen } \\
\text { terbukti sangat } \\
\text { disukai dan } \\
\text { secara praktis } \\
\text { dominasinya } \\
\text { sangat nyata, } \\
\text { dibandingkan } \\
\text { dengan elemen } \\
\text { pasangannya }\end{array}$ \\
\hline 9 & $\begin{array}{ll}\text { Mutlak } & \text { leboh } \\
\text { penting } & \end{array}$ & $\begin{array}{l}\text { Satu elemen } \\
\text { terbukti mutlak } \\
\text { lebih disukai } \\
\text { dibandingkan } \\
\text { dengan } \\
\text { pasangannya, }\end{array}$ \\
\hline
\end{tabular}




\begin{tabular}{|c|c|c|}
\hline & & $\begin{array}{l}\text { pada keyakinan } \\
\text { tertinggi. }\end{array}$ \\
\hline $2,4,6,8$ & Nilai Tengah & $\begin{array}{l}\text { Diberikan bila } \\
\text { terdapat } \\
\text { keraguan } \\
\text { penilaian } \\
\text { antra } \\
\text { tingkat } \\
\text { kepentingan } \\
\text { yang } \\
\text { berdekatan. }\end{array}$ \\
\hline
\end{tabular}

Penilaian dalam membandingkan antara satu kriteria dengan kriteria yang lain adalah bebas satu sama lain, hal ini dapat mengarah pada ketidak konsistensian. Saaty (1990) telah membuktikan bahwa indeks konsistensi dari matrik ber ordo $\mathrm{n}$ dapat diperoleh dengan rumus :

$\mathrm{CI}=(\lambda$ maks-n)$(\mathrm{n}-1)$

Dimana :

CI Indeks Konsistensi ( Consistensy Index)

$\Lambda$ maks $=$ Nilai eigen terbesar dari matrik berordo $\mathrm{n}$.

Nilai eigen terbesar didapat dengan menjumlahkan hasil perkalian jumlah kolom dengan eigen vector. Batas ketidak konsistenan di ukur dengan menggunakan rasio konsistensi (CR), yakni perbandingan Indeks Konsistensi (CI) dengan nilai ppembangkit random (RI). Nilai ini bergantung pada ordo matrik $n$.

Rasio konsistensi dapat dirumuskan :

$\mathrm{CR}=\mathrm{CI} / \mathrm{RI}$.

Bila nilai CR lebih kecil dari $10 \%$, ketidak konsistensian pendapat masih dianggap dapat diterima.

Tabel 2 Index Random Konsistensi

\begin{tabular}{|c|c|c|c|c|c|c|c|c|c|c|c|c|c|c|c|}
\hline $\mathrm{n}$ & 1 & 2 & 3 & 4 & 5 & 6 & 7 & 8 & 9 & 1 & 1 & 1 & 1 & 1 & 1 \\
& & & & & & & & & & 0 & 1 & 2 & 3 & 4 & 5 \\
\hline $\mathrm{R}$ & 0 & 0 & 0 & 0 & 1 & 1 & 1 & 1 & 1 & 1 & 1 & 1 & 1 & 1 & 1 \\
$\mathrm{I}$ &. &. &. &. &. &. &. &. &. &. &. &. &. &. &. \\
& 0 & 0 & 9 & 1 & 2 & 3 & 4 & 4 & 4 & 5 & 4 & 5 & 5 & 5 \\
& 0 & 0 & 8 & 0 & 2 & 4 & 2 & 1 & 5 & 9 & 1 & 8 & 6 & 7 & 9 \\
\hline
\end{tabular}

Adapun Metode penelitian yang penulis lakukan adalah melakukan pengumpulan data berdasarkan jenis datanya, data yang dikumpulkan dalam penelitian ini adalah sebagai berikut:

1. Data Primer

Data primer adalah data yang diambil langsung dari obyek penelitian atau merupakan data yang berasal dari sumber asli atau pertama. Teknik pengumpulan data primer dilakukan melalui teknik observasi dengan cara mengumpulkan informasi informasi langsung ke lokasi penelitian untuk mengamati bagaimana penentuan kualitas pelayanan terhadap nasabah yang dilakukan oleh pihak Bank BCA dengan cara pengamatan dan pencatatan dengan peninjauan langsung dan wawancara dengan melakukan wawancara terstruktur dengan menyediakan daftar pertanyaan untuk mewawancarai petugas atau karyawan/ti dari bank BCA mengenai bagaimana menentukan kualitas pelayan yang diterapkan selama ini. Data yang dihasilkan yaitu informasi berupa opini dari pihak tersebut.

2. Data Sekunder

Data sekunder adalah data yang tidak didapatkan secara langsung dari objek penelitian, melainkan data yang berasal dari sumber yang telah dikumpulkan oleh pihak lain. Teknik pengumpulan data sekunder dilakukan dengan cara studi dokumentasi dan studi literatur.

\section{HASIL DAN PEMBAHASAN}

\subsection{ANALISA DAN PERANCANGAN SISTEM}

Menentukan kepuasan nasabah terhadap kualitas pelayanan ada PT. Bank Central Asia, TBK Pekanbaru, di gunakan beberapa criteria yakni, Fokus (Focus) pada nasabah, Solusi (Solution) yang diberikan kepada nasabah, ketepatan (Accuracy) dalam menyampaikan berbagai informasibaik., waktu (time) pelayanan yang cepat dan dapat menjelaskan bebagai macam produk BCA dengan jelas (Explanation).

Setelah ditetapkan beberapa criteria, maka dilakukan pemberian nilai atau bobot masing-masing criteria untuk setiap alternative yang ada, langkah selanjutnya adalah melakukan proses analisa terhadap system yang dibuat, hasil atau output system adalah informasi mengenai nilai dari alternative bank dan criteria yang dimilikinya untuk dijasikan sebagai bank yang memiliki kualitas pelayanan yang terbaik

\subsection{ANALISA MASUKAN SYSTEM}

Masukan sistem adalah berupa data yang terdiri dari data kriteria dan alternative. Adapun data yang diperlukan 
untuk menentukan kepuasan nasabah terhadap kualitas pelayanan adalah:

1. Data nilai Kriteria

Kriteria yang ada merupakan rincian dari permasalahan penentuan bank yang memiliki kualitas pelayanan berdasarkan beberapa factor. Kriteria-kriteria yang ada terdiri dari
a. Fokus (Focus)
b. Solusi (Solution)
c. Ketepatan (Accuracy)
d. Waktu (Time)
e. Kejelasan (Axplanation)

2. Alternatif jenis sebagai pilihan bank yang dijasikan sebagai bank yang memiliki kualitas pelayanan terhadap nasabah adalah 3 cabang yaitu, Cabang Juanda, Cabang A. Yani dan Cabang RBC.

Tabel 3 Skala Perbandingan Kriteria

\begin{tabular}{|c|c|c|c|c|c|}
\hline Goals & $\mathrm{F}$ & $\mathrm{S}$ & $\mathrm{A}$ & $\mathrm{T}$ & $\mathrm{E}$ \\
\hline $\mathrm{F}$ & 1 & & & & \\
\hline $\mathrm{S}$ & & 1 & & & \\
\hline $\mathrm{A}$ & & & 1 & & \\
\hline $\mathrm{T}$ & & & & 1 & \\
\hline $\mathrm{E}$ & & & & & 1 \\
\hline
\end{tabular}

table diatas kemudian dijasikan sebuah matriks berpasangan untuk dijadikan dasar perhitungan selanjutnya. Pengisian table matrik skala perbandingan

1. Menganalisa Matriks Perbandingan berpasangan 5 Jenis Kriteria Tahap ini pemberian bobot masing- masing kriteria menggunakan model AHP (Analyticaly Hierarki Process). Data kriteria didapat dari pihak perusahaan yang langsung membandingkan kriteria dan kriteria sesuai dengan table kepentingan dan sampel hasil matriks berpasangan

Tabel 4.Matrik Skala Perbandingan Berpasangan Kriteria

\begin{tabular}{|c|c|c|c|c|c|}
\hline Kriteria & $\mathrm{F}$ & $\mathrm{S}$ & $\mathrm{A}$ & $\mathrm{T}$ & $\mathrm{E}$ \\
\hline $\mathrm{F}$ & 1 & $1 / 2$ & $1 / 4$ & $1 / 8$ & $1 / 16$ \\
\hline $\mathrm{S}$ & 2 & 1 & $1 / 2$ & $1 / 4$ & $1 / 8$ \\
\hline $\mathrm{A}$ & 4 & 3 & 1 & $1 / 2$ & $1 / 4$ \\
\hline $\mathrm{T}$ & 8 & 4 & 2 & 1 & $1 / 2$ \\
\hline $\mathrm{E}$ & 16 & 8 & 4 & 2 & 1 \\
\hline
\end{tabular}

Tabel 5. Matrik Berpasangan Alternatif Berpasangan kriteria dalam bentuk desimal

\begin{tabular}{|c|c|c|c|c|c|}
\hline Kriteria & $\mathrm{F}$ & $\mathrm{S}$ & $\mathrm{A}$ & $\mathrm{T}$ & $\mathrm{E}$ \\
\hline $\mathrm{F}$ & 1 & 0.5 & 0.25 & 0.125 & 0.0625 \\
\hline $\mathrm{S}$ & 2 & 1 & 0.5 & 0.25 & 0.125 \\
\hline $\mathrm{A}$ & 4 & 2 & 1 & 0.5 & 0.25 \\
\hline $\mathrm{T}$ & 8 & 4 & 2 & 1 & 0.5 \\
\hline $\mathrm{E}$ & 16 & 8 & 4 & 2 & 1 \\
\hline Total & 31 & 15.5 & 7.75 & 3.8750 & 1.9375 \\
\hline
\end{tabular}

Setelah mengisi table skala perbandingan diatas kemudian dilanjutkan dengan mencari nilai eigen factor.

Tabel 6. Prioritas Kriteria dan Nilai Kriteria

\begin{tabular}{|c|c|c|c|c|c|c|}
\hline $\begin{array}{c}\text { Krit } \\
\text { eria }\end{array}$ & $\mathrm{F}$ & $\mathrm{S}$ & $\mathrm{A}$ & $\mathrm{T}$ & $\mathrm{E}$ & $\mathrm{EF}$ \\
\hline \multirow{2}{*}{$\mathrm{F}$} & 0.0 & 0.0 & 0.0 & 0.0 & 0.0 & 0.0 \\
& 323 & 323 & 323 & 323 & 323 & 323 \\
\hline \multirow{2}{*}{$\mathrm{S}$} & 0.0 & 0.0 & 0.0 & 0.0 & 0.0 & 0.0 \\
& 645 & 645 & 645 & 645 & 645 & 645 \\
\hline \multirow{2}{*}{$\mathrm{A}$} & 0.1 & 0.1 & 0.1 & 0.1 & 0.1 & 0.1 \\
& 290 & 290 & 290 & 290 & 290 & 290 \\
\hline \multirow{2}{*}{$\mathrm{T}$} & 0.2 & 0.2 & 0.2 & 0.2 & 0.2 & 0.2 \\
& 581 & 581 & 581 & 581 & 581 & 581 \\
\hline \multirow{2}{*}{$\mathrm{E}$} & 0.5 & 0.5 & 0.5 & 0.5 & 0.5 & 0.5 \\
& 161 & 161 & 161 & 161 & 161 & 161 \\
\hline \multirow{2}{*}{ Tot } & 1.0 & 1.0 & 1.0 & 1.0 & 1.0 & 1.0 \\
& 000 & 000 & 000 & 000 & 000 & 000 \\
\hline
\end{tabular}

Table ini diisi dengan cara membagi bobot kriteria dengan jumlah bobot kriteria sebagai contoh 0.0323 pada kolom kedua dan baris kedua didapat dari total nilai kriteria dibagi dengan nilai kriteri focus yaitu $1 / 31=$ 0.0323 , begitu selanjutnya dengan hasil total semuanya kriteria adalah 1 nilai eigen factor didapat dari menjumlahkan semua nilai keriteria secara vertical lalu membaginya dengan jumlah kriteria, maka didapatlah hasil 0.0323 .

$\Lambda$ maks $=(31 * 0.0323)+(15.5 * 0.0645)+(7.75 * 0$. $1290)+(3.8750 * 0.2581)+(1.9375 * 0.5161)=$ 5.0009

$\mathrm{CI}=(5.0009-5 /(5-1))=0.000225$

CR $=0.000225: 0.9=0.00025<1$

\section{Konsisten}

2. Menganalisa matrik perbandingan berpasangan berdasarkan kriteria focus

Tabel 7 Matrik Skala Perbandingan

Berpasangan Kriteria Focus

\begin{tabular}{|c|c|c|c|}
\hline Cabang & Rbc & Juanda & A.Yani \\
\hline Rbc & 1 & $1 / 2$ & $1 / 3$ \\
\hline Juanda & 2 & 1 & $1 / 4$ \\
\hline A.Yani & 3 & 4 & 1 \\
\hline
\end{tabular}


Tabel 8 Matrik Berpasangan Alternatif

Berpasangan kriteria focus dalam bentuk decimal

\begin{tabular}{|c|c|c|c|}
\hline Cabang & Rbc & Juanda & A.Yani \\
\hline Rbc & 1 & 0.5 & 0.33 \\
\hline Juanda & 2 & 1 & 0.25 \\
\hline A.yani & 3 & 4 & 1 \\
\hline Total & 6 & 5.5 & 1.58 \\
\hline
\end{tabular}

Tabel 9 Hasil Analisa Alternative Berdasarkan Kriteria Focus

\begin{tabular}{|c|c|c|c|c|}
\hline Cab & RBC & $\begin{array}{c}\text { Juand } \\
\mathrm{a}\end{array}$ & $\begin{array}{c}\text { A.Ya } \\
\text { ni }\end{array}$ & EF \\
\hline RBC & 1.667 & 0.090 & 0.2089 & 0.155 \\
& & 9 & & 5 \\
\hline $\begin{array}{c}\text { Juand } \\
\text { a }\end{array}$ & $\begin{array}{c}0.333 \\
3\end{array}$ & $\begin{array}{c}0.181 \\
8\end{array}$ & 0.1582 & 0.224 \\
\hline A.Ya & 0.500 & 0.727 & 0.6329 & 0.620 \\
ni & 0 & 3 & & 1 \\
\hline Total & 1 & 1 & 1 & 1 \\
\hline
\end{tabular}

$\Lambda$ maks $=$

$(6 * 0.1555)+(5.5 * 0.2244)+(1.58 * 0.6201)$

$=3.1470$

$\mathrm{CI}=(3.1475-3) /(3-1))=0.0735$

CR $=0.0735: 058=0.8621<1$ Konsisten

3. Menganalisa matrik perbandingan berpasangan berdasarkan kriteria

Solution

Tabel 10. Matrik Skala Perbandingan Berpasangan Kriteria solution

\begin{tabular}{|c|c|c|c|}
\hline Cabang & Rbc & Juanda & A.Yani \\
\hline Rbc & 1 & $1 / 3$ & $1 / 5$ \\
\hline Juanda & 3 & 1 & $1 / 4$ \\
\hline A.Yani & 5 & 4 & 1 \\
\hline
\end{tabular}

Tabel 11. Matrik Berpasangan Alternatif

Berpasangan kriteria solution dalam bentuk decimal

\begin{tabular}{|c|c|c|c|}
\hline Cabang & Rbc & Juanda & A.Yani \\
\hline Rbc & 1 & 0.3333 & 0.2000 \\
\hline Juanda & 3 & 1 & 0.25 \\
\hline A.yani & 5 & 4 & 1 \\
\hline Total & 9 & 5.3333 & 1.4500 \\
\hline
\end{tabular}

Tabel 12. Hasil Analisa Alternative

Berdasarkan Kriteria Soution

\begin{tabular}{|c|c|c|c|c|}
\hline $\begin{array}{c}\text { Caban } \\
\mathrm{g}\end{array}$ & RBC & $\begin{array}{c}\text { Juan } \\
\text { da }\end{array}$ & $\begin{array}{c}\text { A.Ya } \\
\text { ni }\end{array}$ & EF \\
\hline RBC & $\begin{array}{c}0.111 \\
1\end{array}$ & $\begin{array}{c}0.662 \\
5\end{array}$ & $\begin{array}{c}0.137 \\
9\end{array}$ & $\begin{array}{c}0.103 \\
8\end{array}$ \\
\hline $\begin{array}{c}\text { Juand } \\
\text { a }\end{array}$ & $\begin{array}{c}0.333 \\
3\end{array}$ & $\begin{array}{c}0.187 \\
5\end{array}$ & $\begin{array}{c}0.172 \\
4\end{array}$ & $\begin{array}{c}0.231 \\
1\end{array}$ \\
\hline A.Ya & 0.555 & 0.750 & 0.689 & 0.689 \\
\hline
\end{tabular}

\begin{tabular}{|c|c|c|c|c|}
\hline ni & 6 & 0 & 7 & 7 \\
\hline Total & 1 & 1 & 1 & 1 \\
\hline
\end{tabular}

$\Lambda \mathrm{maks}=$

$(9 * 0.1038)+(5.3333 * 0.2311)+(1.3500 * 0$.

$6651)=2.4660$

$\mathrm{CI}=(2.4660-2 /(2-1))=0.4660$

CR $=0.4660: 0.58=0.8034<1$

Konsisten

4. Menganalisa matrik perbandingan berpasangan berdasarkan kriteria Accury (Ketepatan)

Tabel 13. Matrik Skala Perbandingan Berpasangan Kriteria Accurary

\begin{tabular}{|c|c|c|c|}
\hline Cabang & Rbc & Juanda & A.Yani \\
\hline Rbc & 1 & $1 / 6$ & $1 / 6$ \\
\hline Juanda & 6 & 1 & $1 / 5$ \\
\hline A.Yani & 6 & 5 & 1 \\
\hline
\end{tabular}

Tabel 14. Matrik Berpasangan Alternatif Berpasangan kriteria Accurary dalam bentuk decimal

\begin{tabular}{|c|c|c|c|}
\hline Cabang & Rbc & Juanda & A.Yani \\
\hline Rbc & 1 & 0.1667 & 0.1667 \\
\hline Juanda & 6 & 1 & 0.2000 \\
\hline A.yani & 6 & 5 & 1 \\
\hline Total & 13 & 6.1667 & 1,3667 \\
\hline
\end{tabular}

Tabel 15 Hasil Analisa Alternative Berdasarkan Kriteria Accurary

\begin{tabular}{|c|c|c|c|c|}
\hline $\begin{array}{c}\text { Caban } \\
\mathrm{g}\end{array}$ & RBC & $\begin{array}{c}\text { Juand } \\
\mathrm{a}\end{array}$ & $\begin{array}{c}\text { A.Yan } \\
\mathrm{i}\end{array}$ & EF \\
\hline RBC & 0.076 & 0.027 & 0.122 & 0.075 \\
& 9 & 0 & 0 & 3 \\
\hline Juanda & 0.461 & 0.162 & 0.146 & 0.256 \\
& 5 & 2 & 3 & 7 \\
\hline A.Yan & 0.461 & 0.810 & 0.731 & 0.668 \\
$\mathrm{i}$ & 5 & 8 & 7 & 0 \\
\hline Total & 1.000 & 1.000 & 1.000 & 1.000 \\
& 0 & 0 & 0 & 0 \\
\hline
\end{tabular}

$\Lambda$ maks $=$

$(13 * 0.0753)+(6.1667 * 0.2567)+(1,3667+0.66$

$80)=3.4749$

$\mathrm{CI}=(3.4749-3) /(3-1))=0.2375$

$\mathrm{CR}=0.2375: 0.58=0.4095<1$ Konsisten

5. Menganalisa matrik perbandingan berpasangan berdasarkan kriteria Time (Waktu)

Tabel 16. Matrik Skala Perbandingan Berpasangan Kriteria Time

\begin{tabular}{|c|c|c|c|}
\hline Cabang & Rbc & Juanda & A.Yani \\
\hline Rbc & 1 & $1 / 3$ & $1 / 6$ \\
\hline Juanda & 3 & 1 & $1 / 3$ \\
\hline A.Yani & 6 & 3 & 1 \\
\hline
\end{tabular}


Tabel 17. Matrik Berpasangan Alternatif Berpasangan kriteria Time dalam bentuk decimal

\begin{tabular}{|c|c|c|c|}
\hline Cabang & Rbc & Juanda & A.Yani \\
\hline Rbc & 1 & 0.3333 & 0.1667 \\
\hline Juanda & 2 & 1 & 0.3333 \\
\hline A.yani & 6 & 3 & 1 \\
\hline Total & 10 & 4.3333 & 1.5 \\
\hline
\end{tabular}

Tabel 18. Hasil Analisa Alternative Berdasarkan Kriteria Time (Waktu)

\begin{tabular}{|c|c|c|c|c|}
\hline Cabang & RBC & Juanda & A.Yani & EF \\
\hline RBC & 0.1 & 0.0769 & 0.1111 & 0.0960 \\
\hline Juanda & 0.2 & 0.2308 & 0.2222 & 0.2510 \\
\hline A.Yani & 0.6 & 0.6923 & 0.6667 & 0.6530 \\
\hline Total & 1.0000 & 1.0000 & 1.0000 & 1.0000 \\
\hline Mmaks $=$ \\
$\left(10^{*} 0.0960\right)+(4.3333 * 0.2510)+(1.5 * 0.6530)$ \\
$=3.0272$ \\
CI $=(3.0272-3) / 3-1))=0.0272$ \\
CR $=0.0135: 0.58=0.0233<1$ Konsisten
\end{tabular}

6. Menganalisa matrik perbandingan berpasangan berdasarkan kriteria Expanation (Penjelasan)

Tabel 19. Matrik Skala Perbandingan Berpasangan Kriteria Explanation

\begin{tabular}{|c|c|c|c|}
\hline Cabang & Rbc & Juanda & A.Yani \\
\hline Rbc & 1 & 3 & 6 \\
\hline Juanda & $1 / 3$ & 1 & 4 \\
\hline A.Yani & $1 / 6$ & $1 / 4$ & 1 \\
\hline
\end{tabular}

Tabel 20 Matrik Berpasangan Alternatif Berpasangan kriteria Explanation dalam bentuk decimal

\begin{tabular}{|c|c|c|c|}
\hline Cabang & Rbc & Juanda & A.Yani \\
\hline Rbc & 1 & 3 & 6 \\
\hline Juanda & 0.3333 & 1 & 4 \\
\hline A.yani & 1.1667 & 0.25 & 1 \\
\hline Total & 1.5 & 4.25 & 11 \\
\hline
\end{tabular}

Tabel 21. Hasil Analisa Alternative

Berdasarkan Kriteria Explanation

\begin{tabular}{|c|c|c|c|c|}
\hline Cab & $\begin{array}{c}\text { RB } \\
\text { C }\end{array}$ & $\begin{array}{c}\text { Juan } \\
\text { da }\end{array}$ & A.Yani & EF \\
\hline RBC & $\begin{array}{c}0.66 \\
0.70\end{array}$ & 0.5455 & 0.6394 \\
& 67 & 59 & & \\
\hline $\begin{array}{c}\text { Juan } \\
\text { da }\end{array}$ & $\begin{array}{c}0.22 \\
22\end{array}$ & $\begin{array}{c}0.23 \\
53\end{array}$ & 0.3636 & 0.2737 \\
\hline $\begin{array}{c}\text { A.Y } \\
\text { ani }\end{array}$ & $\begin{array}{c}0.11 \\
11\end{array}$ & $\begin{array}{c}0.05 \\
88\end{array}$ & 0.0909 & 0.0869 \\
\hline ToT & $\begin{array}{c}1.00 \\
0\end{array}$ & $\begin{array}{c}1.00 \\
0\end{array}$ & 1.000 & 1.000 \\
\hline
\end{tabular}

$\Lambda$ maks $=(1.5 * 0.639)+(4.25 * 0.2737)+(11 * 0.08$

69) $=3.0782$

$\mathrm{CI}=(3.0782-3) /(3-1))=0.0391$

CR $=0.0391: 0.58=0.0674<1$ Konsisten
Tabel 22. Nilai Matriks Keriteria Dengan Cabang Bank

\begin{tabular}{|c|c|c|c|c|c|}
\hline & $\begin{array}{c}\text { Foc } \\
\text { us }\end{array}$ & $\begin{array}{c}\text { Solut } \\
\text { ion }\end{array}$ & $\begin{array}{c}\text { Accu } \\
\text { ary }\end{array}$ & $\begin{array}{c}\text { Tim } \\
\text { e }\end{array}$ & $\begin{array}{c}\text { Explana } \\
\text { tion }\end{array}$ \\
\hline $\begin{array}{c}\text { RB } \\
\text { C }\end{array}$ & $\begin{array}{c}0.15 \\
55\end{array}$ & $\begin{array}{c}0.103 \\
8\end{array}$ & $\begin{array}{c}0.075 \\
3\end{array}$ & $\begin{array}{c}0.09 \\
60\end{array}$ & 0.6394 \\
\hline $\begin{array}{c}\text { Juan } \\
\text { da }\end{array}$ & $\begin{array}{c}0.22 \\
44\end{array}$ & $\begin{array}{c}0.231 \\
1\end{array}$ & $\begin{array}{c}0.256 \\
7\end{array}$ & $\begin{array}{c}0.25 \\
10\end{array}$ & 0.2737 \\
\hline $\begin{array}{c}\text { A.Y } \\
\text { ani }\end{array}$ & $\begin{array}{c}0.62 \\
01\end{array}$ & $\begin{array}{c}0.689 \\
7\end{array}$ & $\begin{array}{c}0.668 \\
0\end{array}$ & $\begin{array}{c}0.65 \\
30\end{array}$ & 0.0869 \\
\hline $\begin{array}{c}\text { Tota } \\
1\end{array}$ & $\begin{array}{c}1.00 \\
00\end{array}$ & $\begin{array}{c}1.000 \\
0\end{array}$ & $\begin{array}{c}1.000 \\
0\end{array}$ & $\begin{array}{c}1.00 \\
00\end{array}$ & 1.0000 \\
\hline
\end{tabular}

Pengisian table ini dilakukan dengan cara mengambil eigen vactor dari masing-masing kriteria

Tabel 23. Nilai Eigen Factor semua kriteria

\begin{tabular}{|l|l|}
\hline Kriteria & Eigen Factor \\
\hline Focus & 0.0323 \\
\hline Solution & 0.0645 \\
\hline Accuary & 0.1290 \\
\hline Time & 0.2581 \\
\hline Explanation & 0.5161 \\
\hline Total & 1,0000 \\
\hline
\end{tabular}

Langkah selanjutnya dengan melakukan perkalian matriks antara table 22 dengan table 23

$\mathrm{RBC}=$

$555 * 0.0323)+(0.1038 * 0.0645)+(0.0753 * 0.12$

$90)+(0.0960 * 0.2581)+(0.6394 * 0.5161)=$

0.3762

Juanda $=$

$(0.2244 * 0.0323)+(0.2311 * 0.0645)+(0.2567 * 0$

$.1290)+(0.2510 * 0.2581)+(0.2737 * 0.5161)$

$=0.2613$

A. Yani $=$

$(0.6201 * 0.0323)+(0.6897 * 0.0645)+(0.6680 * 0$

$.1290)+(0.6530 * 0.2581)+(0.0869 * 0.5161)$

$=0.3640$

7. Dari pengujian diatas rengking dan bobot penentuan kualitas pelayanan pada bank BCA Pekanbaru adalah bank BCA cabang $\mathrm{RBC}$ yang berada pada tingkat pertama

Tabel 24. Perengkingan

\begin{tabular}{|l|l|l|}
\hline No & Cabang & Rengking \\
\hline 1 & RBC & 0.3762 \\
\hline 2 & A. Yani & 0.3640 \\
\hline 3 & Juanda & 0.2613 \\
\hline
\end{tabular}

\section{SIMPULAN}

Berdasarkan hasil perancangan dan implementasi terhadap system pendukung keputusan menentukan kualitas pelayanan 
pada bank dengan metode analytical hierarcy Process ini peneliti menarik kesimpulan sebagai berikut :

1. Dengan menggunakan metode analytical Hierarchy Process ini pengolahan data menentukan kualitas pelayanan bank terhadap nasabahdapat dilakukan dengan cepat, tepat dan akurat serta menghasilkan informasi yang optimal.

2. Hasil outputnya berupa keputusan dari ketiga cabang, yang mana cabang bank yang memiliki kualitas pelayanan yang terbaik, yang di peroleh dari hasil erbandingan nilai lamda bobot kategori penilaian dengan nilai bobot rasio yang sudah ditentukan.

\section{UCAPAN TERIMAKASIH}

Terima kasih penulis ucapkan kepada Bank Central Asia (BCA) yang membantu penulis untuk memberikan data serta kepada Lemabaga Penelitian dan Pengabdian Masyarakat (LPPM) STIKOM Pelita Indonesia atas dukungan moril maupun materil.

\section{DAFTAR PUSTAKA}

Al Bahra Bin Ladjamudin B., 2006, "Rekayasa Perangkat Lunak", Yogyakarta: Graha Ilmu.

Dita Donita, 2013, Sistem Pendukung Keputusan Penerima Bantuan Langsung Tunai Dengan Menggunakan Metode AHP, Jurnal

Hermawan Ardiyanto, 2013Sistem Pendukung Keputusan Pemilihan Perumahan Menggunakan Metode AHP berbasis WEB (Studi kasus CV Wisma Anungkriya Demak), Journal Of Informatics and Technologi Vol 2, No 3, Tahun 2013
Jogianto. HM.,Analisis dan Desain Sistem Informasi, Andi Offset, Yogyakarta:2000

Nachrowi Djalal Nacrowi, Phd, Hardius Usman, M.Si., 2004, Teknik Pengambilan Keputusan, PT. Grasindo, Anggota Ikap, Jakarta

Sri Eniyati, Rina Candra Noor Santi, 2010, Perancangan Sistem Pendukung Keputusan Penilaian Prestasi Dosen Berdasarkan Penelitian dan Pengabdian Masyarakat, jurnal Teknologi Informasi DINAMIKA, Vol.XV No.2 